\title{
Production of Novel Superelastic Biocompatible Ti-Nb-based Alloys for Medical Application
}

\author{
Anton Konopatskya ${ }^{a}$, Yulia Zhukova, Sergey Dubinsky, Mikhail Filonov, Sergey Prokoshkin \\ National University of Science and Technology “MISIS”, 119049 Leninskiy 4 Moscow, Russia
}

\begin{abstract}
Vacuum induction melting (VIM) and vacuum arc remelting (VAR) methods were used to produce biocompatible Ti-Nb-based alloys. In case of VIM BeO was used as material of crucible, and copper mold cup in case of VAR. Superelastic biocompatible Ti-22Nb-3Ta-3Zr, Ti-22Nb-6Ta and Ti-22Nb-6Zr (at \%) alloys were produced. Samples of obtained alloys were investigated by scanning electron microscopy with XRSMA. It was shown that bulk chemical compositions of all VAR alloys exactly corresponded to their nominal chemical compositions. Element distribution maps showed that there was significant chemical inhomogeneity in VIM samples. On the other hand, VAR samples had no such areas and all elements were distributed homogeneously.
\end{abstract}

\section{Introduction}

There are high special requirements to materials which are used in maxillofacial surgery and arthroplasty. At the moment there is no cardinal solution for the problem of biocompatible material which could replace bone tissue or work in pair with bone tissue. Such materials should exhibit an optimum combination of different functional properties which determine if material is biochemically and biomechanically compatible with bone tissue. Biomechanical compatibility is based on similarity in mechanical behavior and characteristics of implant material and bone tissue. Low elastic modulus and superelastic behavior are the most important among such properties. These properties allow implant to imitate behavior of bone tissue during exploitation. In terms of biochemical compatibility, it is very important to use only safe alloy constituents. Due to these requirements Ti-based alloys have become widely used. Nowadays there are perspective metallic systems among Ti-based alloys which are not completely studied. The Ti-Nb-Ta and $\mathrm{Ti}-\mathrm{Nb}-\mathrm{Zr}$ systems which exhibit superelasticity and contain only safe components seem to be the most promising from this viewpoint [1-3]. These alloys indeed not are as functionally effective as traditional $\mathrm{Ti}-\mathrm{Ni}$ superelastic alloys, however, being subjected to a special thermomechanical treatment, they acquire a nanosubgrained structure which gives them a perfect superelastic behavior $[4,5]$.

Special attention should be paid to the search for rational method of producing biocompatible alloys because the quality of obtained ingot has great influence on material functional properties, their stability and reproducibility. It is also very important to search for the chemical composition of the alloy which can exhibit perfect superelasticity at human body temperature [6]. In the present work, Ti-Nb-Ta and Ti-Nb-Zr alloys were produced by vacuum induction melting and vacuum arc remelting [7-11] and characterized using SEM and X-ray spectral microanalysis.

\section{Experimental Procedure and Results}

Three test ingots of Ti-22Nb-3Ta-3Zr (at. \%) alloys were obtained by vacuum induction melting in «LeyboldHeraeus» furnace using high purity raw materials. Melting and crystallization was carried out in $\mathrm{BeO}$ crucible.

Melt \#1 mass was $105 \mathrm{~g}$, the process has taken 9 min. Some pieces of niobium were not completely remelted that has led to significant deviations from the nominal chemical composition across the ingot section. Melt \#2 mass was $75 \mathrm{~g}$, the process has taken $33 \mathrm{~min}$. Melt \#3 mass was $77 \mathrm{~g}$, the process has taken $34 \mathrm{~min}$. There were a lot of pores on the surfaces of ingots \#2 and 3.

Samples \#2 and 3 were prepared from the ingots \#2 and 3 and studied by scanning electron microscopy with X-ray spectral micro-analysis (XRSMA). Obtained element distribution maps are shown in Figure 1.

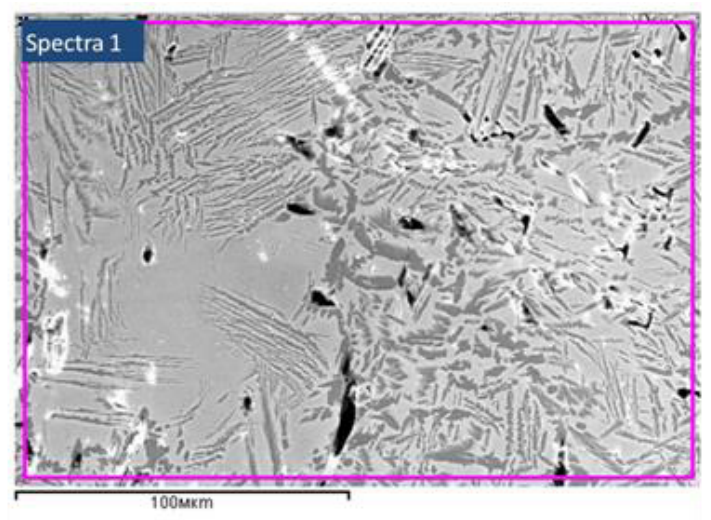

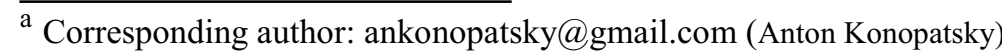



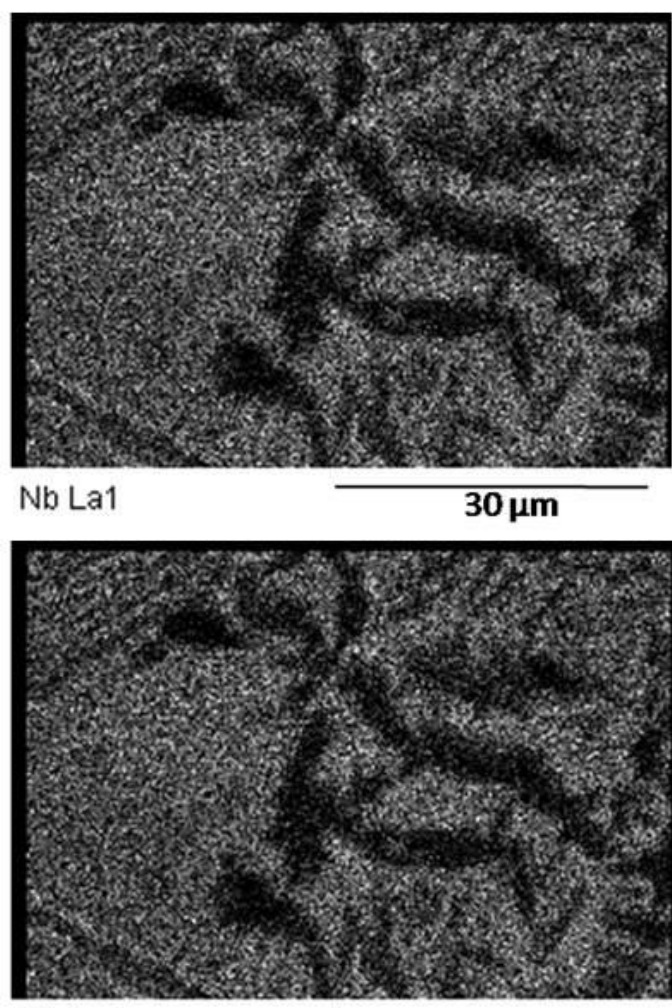

Nb La1

$30 \mu \mathrm{m}$

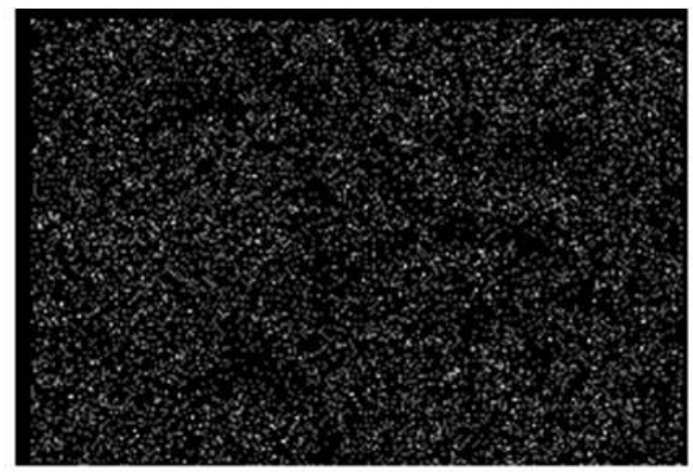

Ta La1

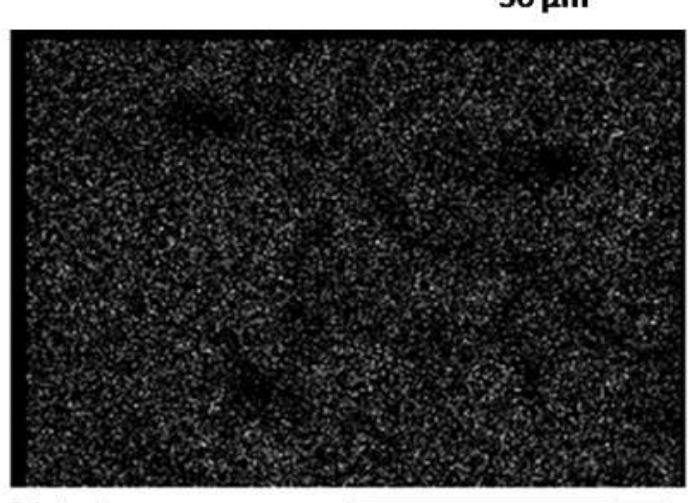

Zr La1

$\mathbf{3 0 \mu \mathrm { m }}$

amount of niobium. Inhomogeneity of $\mathrm{Zr}$ and $\mathrm{Ta}$ was not as noticeable due to low content of these elements in alloy.

Comparison of obtained bulk composition and nominal chemical composition is shown in Table 1.

Table 1. Comparison of obtained and nominal chemical composition, Ti-Nb-Ta-Zr VIM

\begin{tabular}{|c|c|c|}
\hline Element & Obtained [at. \%] & Nominal [at. \%] \\
\hline $\mathrm{Ti}$ & 67.0 & 72 \\
\hline $\mathrm{Nb}$ & 25.5 & 22 \\
\hline $\mathrm{Ta}$ & 3.9 & 3 \\
\hline $\mathrm{Zr}$ & 3.6 & 3 \\
\hline
\end{tabular}

According to Table 1 there is insufficiency of obtained and nominal chemical composition. Additional analysis of mechanical properties is needed to estimate if such insufficiency is crucial for functional properties of the alloy.

It is important to mention that ingots had open and closed porosity. Diameter of pores came up to $2 \mathrm{~mm}$. Such porosity significantly reduces mechanical properties of the material.

Large amount of pores in the ingots, insufficiency of chemical composition and uneven distribution of components in the alloy has led to inevitability of finding another way to produce these alloys.

When searching for the rational method of producing biocompatible alloys, it is important to take into consideration high melting temperatures of the alloy components and their high affinity to oxygen. Thus, vacuum arc remelting (VAR) has been chosen as widely used and reliable method of producing high-reactive and refractory alloys $[12,13]$.

Ingots of $\mathrm{Ti} 22 \mathrm{Nb}-6 \mathrm{Zr}$ and $\mathrm{Ti}-22 \mathrm{Nb}-6 \mathrm{Ta}$ (at. \%) alloys were obtained in vacuum arc furnace with a nonconsumable electrode under argon protective atmosphere. Crystallization was carried out in the water-cooled copper mold. Ti $22 \mathrm{Nb}-6 \mathrm{Zr}$ ingot was remelted 3 times and Ti$22 \mathrm{Nb}-6 \mathrm{Ta}$ alloy ingot was remelted 4 times. Every ingot was turned upside down after each remelting. Mass of each ingot was about $150 \mathrm{~g}$.

The samples from these ingots were studied by scanning electron microscopy with XRSMA and element distribution maps were obtained (Figure 2). Results showed that chemical composition of the alloys was very close to nominal chemical composition and both alloys have high degree of homogeneity. Comparing Figure 1 and Figure 2 which have similar scale we can see that VAR ingot has much higher degree of homogeneity.

Figure 1. Electron image of Ti-Nb-Ta-Zr surface and element distribution maps for Ti-Nb-Ta-Zr.

The results showed that sufficient homogeneity was not reached; there were areas which were depleted with some of the main components. The areas depleted with niobium contained increased amount of titanium while the areas depleted with titanium contained increased 
Electron Image 40

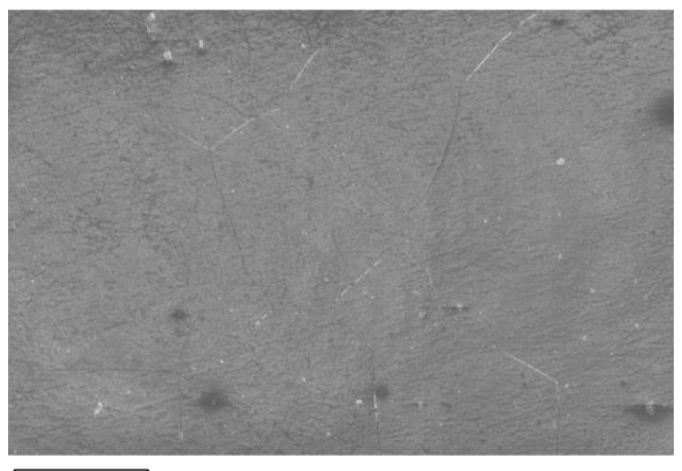

$\mathrm{Ti} K \alpha 1$

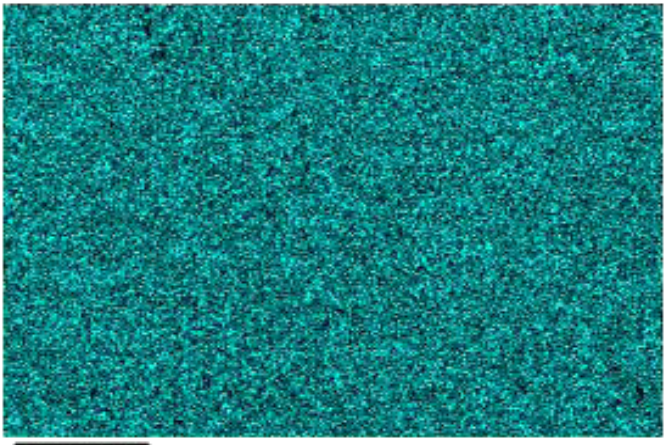

$250 \mu \mathrm{m}$

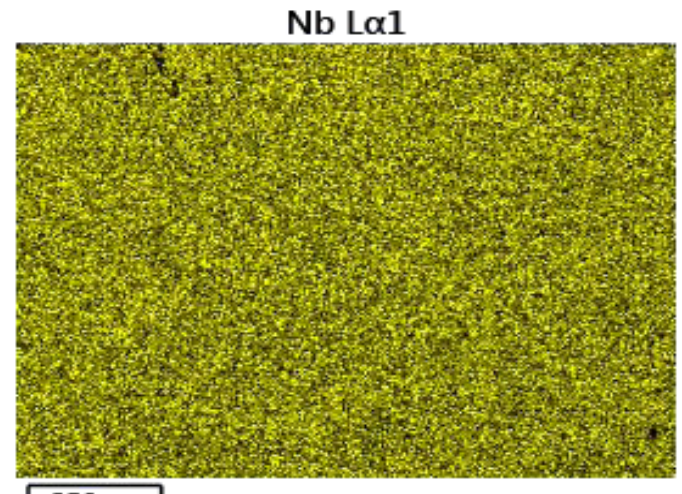

$\longdiv { 2 5 0 \mu \mathrm { m } }$

\section{$\operatorname{Zr} \operatorname{L} \alpha \mathbf{1}$}

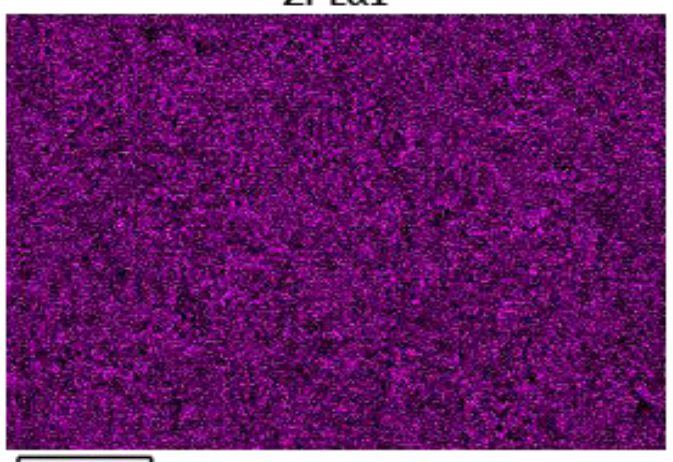

$250 \mu \mathrm{m}$

Figure 2. Electron image of $\mathrm{Ti}-\mathrm{Nb}-\mathrm{Zr}$ surface and element distribution maps for $\mathrm{Ti}-\mathrm{Nb}-\mathrm{Zr}$.

Spectrum on Figure 3 has been received from the area shown on Figure 2. Comparison of obtained chemical composition and nominal chemical composition is shown in Table 2.
Table 2. Comparison of obtained and nominal chemical composition, Ti-Nb-Zr VAR

\begin{tabular}{|c|c|c|}
\hline Element & Obtained [at. \%] & Nominal [at. \%] \\
\hline $\mathrm{Ti}$ & 71.4 & 72 \\
\hline $\mathrm{Nb}$ & 21.4 & 22 \\
\hline $\mathrm{Zr}$ & 7.2 & 6 \\
\hline
\end{tabular}

According to these results obtained chemical composition corresponds to nominal chemical composition to a high precision.

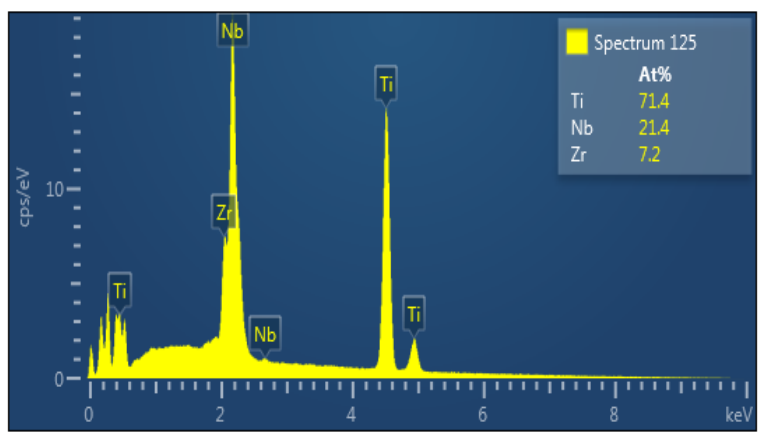

Figure 3. Full spectra for Ti-Nb-Zr.

Similar results for Ti-22Nb-6Ta are shown in Figure 4 and 5 .

Electron Image 59

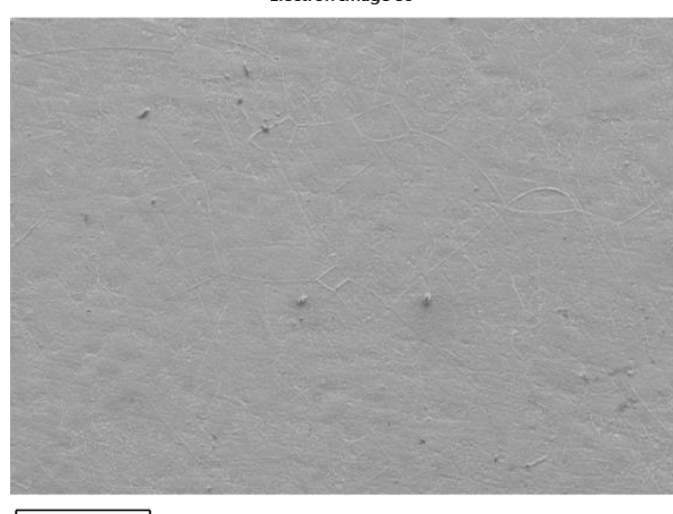

$\mathrm{Ti} K \alpha 1$

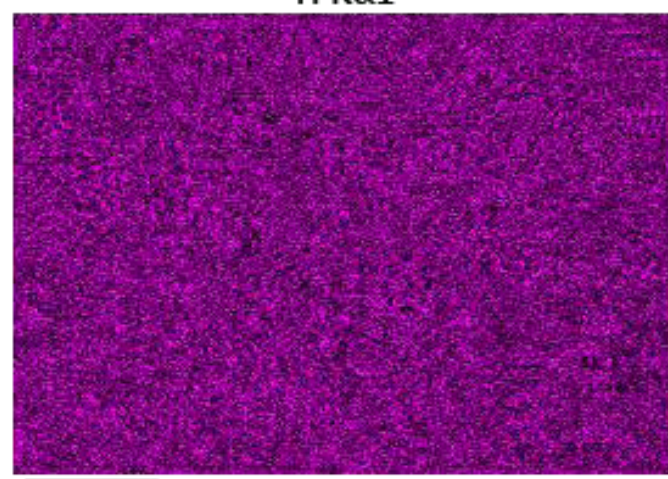

$250 \mu \mathrm{m}$ 


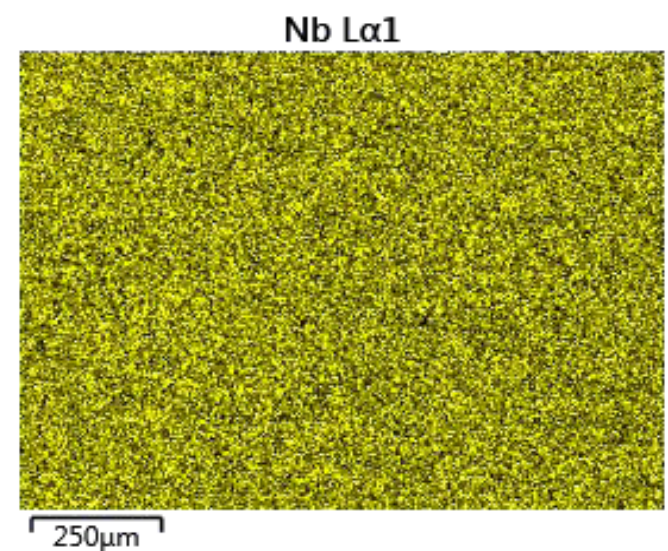

$\mathrm{Ta} \mathrm{M} \alpha \mathbf{1}$

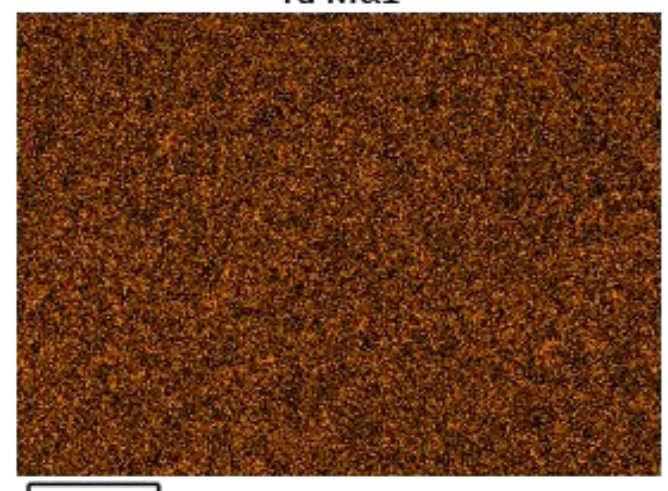

$\longdiv { 2 5 0 \mu \mathrm { m } }$

Figure 4. Electron image of $\mathrm{Ti}-\mathrm{Nb}-\mathrm{Ta}$ surface and element distribution maps for $\mathrm{Ti}-\mathrm{Nb}-\mathrm{Ta}$.

As we can see all of obtained elemental maps do not have areas of enhanced concentration. It allows us to suggest that all components are distributed in the ingot evenly and material won't suffer from anisotropy of properties due to lack or excess amount of one or another element.

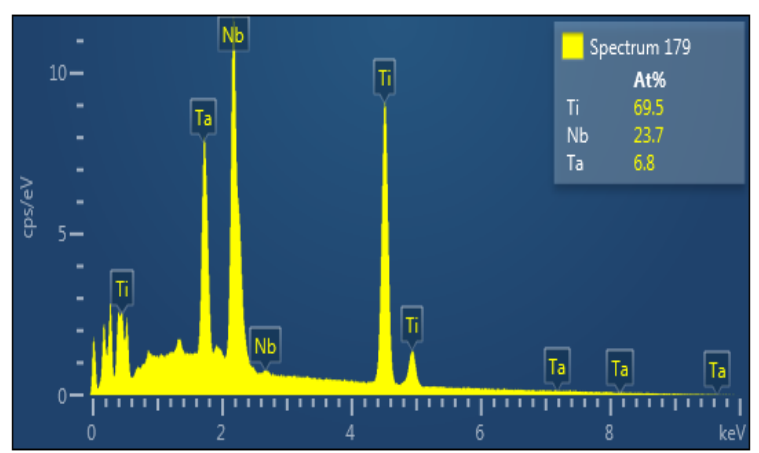

Figure 5. Full spectra for Ti-Nb-Ta.

Comparison of obtained chemical composition and nominal chemical composition is shown in Table 3 .
Table 3 - Comparison of obtained and nominal chemical composition, Ti-Nb-Ta VAR

\begin{tabular}{|c|c|c|}
\hline Element & Obtained [at. \%] & Nominal [at. \%] \\
\hline $\mathrm{Ti}$ & 69.5 & 72 \\
\hline $\mathrm{Nb}$ & 23.7 & 22 \\
\hline $\mathrm{Ta}$ & 6.8 & 6 \\
\hline
\end{tabular}

As we can see in that case match of obtained chemical composition and nominal chemical composition is not as excellent as for Ti-Nb-Zr, which is most likely connected to lower machinability of $\mathrm{Ti}-\mathrm{Nb}$-Ta alloy due to high refractory of Ta.

It is important to notice that VAR may produce ingots with rough surface which is connected to crystallization behavior. Sometimes it is needed to remove up to $3 \mathrm{~mm}$ of such surface.

According to these results ingots of Ti-22Nb-6Ta and Ti-22Nb-6Zr alloys were of a high quality suitable for mechanical testing.

\section{Conclusion}

$\mathrm{Ti}-\mathrm{Nb}$ alloys were produced. Two methods of producing alloys were examined. It was shown that ingots produced by VIM method are characterized by inhomogeneous distribution of all alloys components, high porosity and some insufficiency of obtained and nominal chemical composition. All that leads to conclusion that ingots produced by VIM method did not meet needed requirements. On the other hand analysis of ingots of $\mathrm{Ti}-22 \mathrm{Nb}-6 \mathrm{Ta}$ and $\mathrm{Ti}-22 \mathrm{Nb}-6 \mathrm{Zr}$ alloys produced by VAR showed prospects of this method in producing superelastic Ti-Nb-based alloys for medical application. Those ingots are homogeneous and their chemical composition is in excellent match with nominal chemical composition. Disadvantages of that method (rough surface of ingots) are outweighed by its advantages. At the moment, the development of VAR-based technique for manufacturing these advanced functional materials is in progress.

\section{Acknowledgements}

The work was carried out with financial support from the Ministry of Education and Science of the Russian Federation in the framework of Increase Competitiveness Program of NUST «MISiS» (project No K4-2014-018) and State Task No. 16.1790.2014K.

\section{References}

1.H. Y. Kim, T. Sasaki, K. Okutsu, J. I. Kim, T. Inamura, H. Hosoda and S. Miyazaki, Acta Mater. 54, 423 (2006)

2. J. I. Kim, H. Y. Kim, T. Inamura, H. Hosoda and S. Miyazaki, Mater. Sci. and Eng. A. 403, 334 (2005)

3.H. Y. Kim, J. Fu, H. Tobe, J. I. Kim and S. Miyazaki, Shape Memory and Superelasticity. 1, 107 (2015) 
4.S. Prokoshkin, V. Brailovski, M. Petrzhik, M. Filonov, V. Sheremetyev, Mater. Sci. Forum 738-739, 481 (2013)

5.S. Dubinskiy, V. Brailovski, S. Prokoshkin, V. Pushin, K. Inaekyan, V. Sheremetyev, M. Petrzhik, M. Filonov, J. Mater. Eng. Perform. 22, 2656 (2013)

6. N. Sakaguchi, M. Niinomi, T. Akahori, J. Takeda, H. Toda, Mater. Sci. and Eng. C, 25, 370-376 (2005)

7.T. Maeshima, M. Nishida, Mater. Trans. 45, 1096 (2004)

8.H. Y. Kim, Y. Ohmatsu, J. I. Kim, H. Hosoda, S. Miyazaki, Mater. Trans. 45, 1090 (2004)

9.L. W. Ma, H.S. Cheng, C.Y. Chung, Intermetallics 32, 44 (2013)

10. E. Takashi, T. Sakurai, S. Watanabe, N. Mashashi, Sh. Hanada, Mater. Trans. 43, 2978 (2002)

11. M. Tahara, H. Y. Kim, H. Hosoda, S. Miyazaki, Acta Mater. 57, 2461 (2009)

12. L. Nie, Y. Zhan, T. Hu, X. Chen, C. Wang, J. Mech. Behav. Biomed. 29, 1 (2014)

13. A. Konopatsky, Yu. Zhukova, M. Filonov, Advanced Materials Research 1040, 130 (2014). 
